\title{
CRIAÇÃO E MANUTENÇÃO DA BIBLIOTHECA PÚBLICA PELOTENSE EM JORNAIS DO SÉCULO XIX (1875-1900)
}

\author{
Renata Braz Gonçalves \\ Mestre e Doutora em Educação pela Universidade \\ Federal de Pelotas - UFPel. Professora \\ Associada no Instituto de Ciências Humanas e da \\ Informação da Universidade Federal do \\ Rio Grande - FURG, Brasil. \\ renatabraz@furg.br \\ https://orcid.org/0000-0002-7322-2339
}

\author{
Eliane Teresinha Peres \\ Professora Titular Aposentada da UFPel. Mestra \\ em Educação pela Universidade Federal do \\ Rio Grande do Sul (1995) e Doutora em Educação \\ pela Universidade Federal de Minas Gerais, Brasil. \\ eteperes@gmail.com \\ https://orcid.org/0000-0002-0160-1276
}

\begin{abstract}
RESUMO
Este artigo é derivado de tese já defendida e analisa práticas e representações de leitura no final do século XIX, na cidade de Pelotas (RS), tendo como objeto a criação e a manutenção da Bibliotheca Pública Pelotense, fundada em 1875. A investigação insere-se no campo da História da Leitura, fundamentada na História Cultural. A pesquisa utilizou como fontes os jornais (diários, literários e humorísticos) publicados em Pelotas no período de 1875 a 1900, adotando a Análise de Conteúdo como técnica de análise. Verificou que a criação da biblioteca surgiu da motivação da comunidade que, através da imprensa, promoveu um movimento para suprir "uma lacuna na vida intelectual" citadina. O processo de proposição, criação, construção (com doações, bazares e quermesses) eventos e discussão sobre quem poderia frequentar estão publicados nos jornais. Foram identificadas representações de ilustração, de conhecimento, de luz e de civilização. Além disso, constatou que a biblioteca foi criada para atender todas as classes, e não para uso exclusivo das famílias mais abastadas. Conclui que acompanhar a criação da Bibliotheca e sua manutenção possibilitou conhecer aspectos de uma comunidade que se preocupava com o livro e com o espaço popular destinado à leitura, refutando argumentações equivocadas anteriores que afirmavam que, no século XIX, no Brasil como um todo, não haveria leitura e leitores, tendo em vista que o Rio de Janeiro seria uma "ilha de cultura isolada" em meio à falta generalizada de instituições.
\end{abstract}

Palavras-chave: História da Leitura. História das Bibliotecas. Pelotas.

\section{CREATION AND MAINTENANCE OF THE PELOTENSE PUBLIC LIBRARY IN XIX CENTURY NEWSPAPERS (1875-1900)}

\begin{abstract}
This article analyzes practices and representations of reading at the end of the 19th century, in the city of Pelotas (RS), with the focus in creating and maintaining oh the Bibliotheca Pública Pelotense, founded in 1875. The investigation is inserted in the field of History of Reading, based on Cultural History. The sources used in the research were newspapers (daily, literary and humorous) published in Pelotas between 1875 and 1900, adopting Content Analysis technique. It was verified that the creation of the library was originated from the motivation of the community that, through the press, promoted a movement to fill "a gap in intellectual life" in the city. The process of proposition, creation, construction (with donations, bazaars, and fairs), events and discussion about who could attend are published in the newspapers. Representations of knowledge and civilization were identified. In addition, it was found that the library was created to serve all classes, and not for exclusive wealthy families uses. It concludes that following the creation of the Bibliotheca and its maintenance made it possible to know aspects of a community concerned with the book and with the popular space destined for reading, refuting the previous mistaken arguments that in the 19th century, in Brazil there were no reading and readers, except for Rio de Janeiro wich would be an "isolated culture island" amid the general lack of institutions.
\end{abstract}

Keywords: History of Reading. Libraries History. Pelotas.

Recebido em: 30/09/2020 Aceito em: 27/01/2021 Publicado em: 12/07/2021 


\section{INTRODUÇÃo}

Ao trazermos aspectos da História da Leitura de Pelotas, cidade do interior do Rio Grande do Sul, no século XIX, salientamos que entendemos que a cidade não deve ser vista apenas como lócus, mas como espaço privilegiado de transformação econômico-social. Segundo Pesavento (2007), a cidade representa o que se poderia denominar de um campo de pesquisa e de discussão interdisciplinar, uma vez que trabalham sobre a cidade não só historiadores, mas geógrafos, sociólogos, economistas, urbanistas e antropólogos. O que cabe destacar é a abordagem introduzida pela História Cultural: a cidade não é mais considerada como um lócus seja da realização da produção seja da ação social, mas, sobretudo, como um problema e um objeto de reflexão.

Roche afirma que pesquisas sobre as práticas da escrita em cidades francesas do século XVIII revelam que todas as grandes metrópoles regionais são produtoras e consumidoras de livros, de brochuras e jornais. Dessa forma, deve-se atentar para 0 estudo dessas práticas e representações ligadas à produção e ao consumo desses materiais de leitura nas cidades, uma vez que, segundo o autor, uma série de práticas cotidianas relacionadas entre si passou a ocupar um papel importante no incremento e difusão do impresso (ROCHE, 2001).

A leitura constitui-se em prática cultural, ou seja, cada lugar possui características próprias de ler e pensar a leitura que se manifestam através de práticas e representações. As práticas de leitura realizadas em uma cidade podem não ser as mesmas realizadas em outra, bem como na mesma cidade poderão existir diversas formas de ver, pensar e agir em diferentes períodos da história.

Chartier (1994; 1999; 2001; 2009) considera que a leitura implica diversas competências, nem sempre constantes e homogêneas na história das comunidades que a praticam. Para o autor, importa considerar os protocolos e as comunidades de leitura, as classificações, os regimes de circulação, as exclusões, as censuras da atenção, os tempos, a oralização, a memorização, a leitura silenciosa etc. Os estudos de práticas de leitura, tais como os propostos por Chartier, consideram a leitura como uma atividade humana que tem, portanto, uma história e uma sociologia. A significação é, para esse autor, função direta da "atuação" do leitor ou dos leitores. Para Zilberman (201?), a História da Leitura avança para além do texto, lidando, pelo menos, com uma técnica (a escrita), uma tecnologia (a fixação da escrita em meio permanente) e com uma instituição (a escola). 
Concordamos com a autora e ousamos acrescentar outras instituições, como as igrejas, as famílias e as bibliotecas.

Por um longo período, acreditou-se que práticas de leitura mais efetivas só existiam no Rio de Janeiro, todavia, atualmente, há estudos que contrapõem essa visão sobre a leitura no Brasil. De acordo com Abreu (2007, p.4):

Especialmente quando se estudava o século XIX, percebia-se que cidades como o Rio de Janeiro haviam contado com bibliotecas, gabinetes de leitura, sociedades literárias, livreiros e com uma imprensa que dava vazão à produção local e às traduções do que se publicava no exterior. Os mais pessimistas, entretanto, diziam que o Rio de Janeiro era uma exceção, uma ilha de cultura isolada em meio à falta generalizada de instituições. Considerando o Brasil como um todo não haveria leitura e leitores.

Este artigo constitui-se em recorte de tese que analisou livros e leitura na cidade de Pelotas-RS no final do século XIX, através de jornais pelotenses (GONÇALVES, 2010). Dessa forma, o presente texto tem por objetivo abordar práticas e representações de leitura a partir do movimento de criação e de manutenção da Bibliotheca Pública Pelotense, fundada em 1875 na cidade de Pelotas RS e poderá, além de outros benefícios, como o de contribuir para a historiografia sobre as práticas e representações de leitura no país, ajudar a desmistificar esse senso comum de que, nesse período, no restante do Brasil, não se lia.

\section{PROCEDIMENTOS METODOLÓGICOS}

A partir de uma abordagem qualitativa, esta pesquisa documental teve por objetivo identificar representações de leitura registradas pela imprensa da cidade de Pelotas-RS no final do século XIX. Compuseram o corpus de análise notícias, anúncios, comentários e textos literários publicados nos jornais (comerciais, literários, políticos, noticiosos ou humorísticos) em circulação em Pelotas, entre 1875 e 1900, bem como estatutos e atas de sociedades literárias e da Bibliotheca Pública Pelotense ${ }^{1}$. Utilizou-se, também, o material, organizado pelo professor Rildo Cosson e disponível em CD-ROM, do projeto Literatura, Jornal e Cultura: autores pelotenses - 1851/1889, que teve por objetivo desenvolver um trabalho de recuperação das produções literárias e de nomes de colaboradores que auxiliaram, por meio da imprensa literária da região,

\footnotetext{
${ }^{1}$ A grafia original dos textos do século XIX foi mantida quando necessário.
} 
no desenvolvimento sociocultural de Pelotas e localidades vizinhas ${ }^{2}$. Além dos acervos citados, também foram consultados e analisados os catálogos das Bibliotecas Nacionais do Brasil, da França e de Portugal, nas quais se teve acesso a algumas obras digitalizadas e disponibilizadas na Internet.

No que diz respeito ao uso de jornais como fonte de pesquisa, cabe ressaltar que, além de ser esse o único material a que se teve acesso para a pesquisa, a predominância da circulação desse material de leitura também foi um fator preponderante na escolha dessa fonte de pesquisa sobre história da leitura, uma vez que os jornais se constituíam no meio de comunicação mais viável, pois atingiam um grande e variado público leitor, de acordo com Cunha (2004, p.117). Essa profusão de produção e de circulação de jornais também é comentada por Chartier (2002b, p.30) quando diz que, ao tornar os produtos de impressão mais baratos e disponíveis, por exemplo, a um consumidor "popular" (primeiro os livretos para venda ambulante; mais tarde, as coleções populares e os jornais), ofereceu-se ao público um número cada vez mais amplo e diversificado de materiais de leitura.

A imprensa possuía um papel de destaque na sociedade, ela objetivava promover, divulgar e julgar muitos acontecimentos, considerando-se uma "neutra prestadora de serviço à comunidade". Para Maria Helena Câmara Bastos (2002, p.171),

Os periódicos [...], além de serem um produto de consumo, são, sobretudo, um veículo de ideias e mensagens, um discurso que permite a formação de outros discursos, enunciados que ecoam e reverberam efeitos no dia a dia, na reconstrução cotidiana de laços sociais, na identidade de leitor/leitora.

Nessa perspectiva, entende-se que esses enunciados que eram veiculados no jornal mostravam as representações do cotidiano e da leitura. A partir da análise dos jornais, depreende-se o quão é importante a utilização dessa fonte, fazendo que se ampare a seguinte afirmativa de Vilar:

A rigor, não é mais possível escrever uma história do romantismo e da vida cultural brasileira oitocentista sem a consulta aos jornais da época, principalmente, se quisermos reconstituir de forma não anacrônica e mais verossímil aquele período. Os periódicos foram fundamentais no estabelecimento dessa estética, determinando basicamente todo 0 processo de circulação dos bens materiais e simbólicos. Esse processo inclui desde a criação de gêneros literários ao estabelecimento do gosto pela ficção, além de práticas de leitura e de escrita próprias e peculiares (VILAR, 2008, p.15).

${ }^{2} \mathrm{O}$ CD-Rom ainda não foi publicado e foi cedido pelo Dr. Artur Emilio Alarcon Vaz, professor do Instituto de Letras e Artes da FURG. 
Considerando a representação do valor atribuído à imprensa na época, bem como à relevância do uso da imprensa como fonte para a história da leitura pelotense - visto que era a única fonte a qual se tinha acesso capaz de recuperar as representações de leitura e leitores em Pelotas no final do século XIX - é que se optou, para a constituição do corpus desta pesquisa, por uma seleção de títulos de jornais publicados, em Pelotas, no século XIX. Esses periódicos estão armazenados no Museu da Bibliotheca Publica Pelotense e na Biblioteca Publica Rio-Grandense.

Diante do acima exposto, considera-se que o jornal é elemento indispensável para o estudo da história da leitura de Pelotas no final do século XIX, pois traz, em suas páginas, o registro do processo de produção e da circulação dos materiais de leitura e das formas de pensar e agir em relação a essa prática cultural.

Vale salientar que as coleções estão incompletas em virtude da decomposição causada pelo tempo e pelas precárias condições de armazenagem e manuseio a que esses documentos foram submetidos ao longo dos anos. Dessa forma, o recorte cronológico se estabelece pela disponibilidade das fontes e pela data de criação da biblioteca, que é de 1875, estendendo-se até o final do século XIX.

Os jornais e exemplares consultados para essa investigação estão especificados no seguinte quadro:

Quadro 1 - Títulos, período e características dos periódicos analisados disponíveis no Acervo da Bibliotheca Pública Pelotense

\begin{tabular}{|l|l|l|l|}
\hline No & \multicolumn{1}{|c|}{ Títulos } & $\begin{array}{c}\text { Período (semestres } \\
\text { disponíveis } \\
\text { para pesquisa) }\end{array}$ & \multicolumn{1}{|c|}{$\begin{array}{c}\text { Observações (Tipo de jornal, temas } \\
\text { privilegiados, periodicidade): }\end{array}$} \\
\hline 1 & Correio Mercantil & $1875-1900$ (49 sem) & Comercial e noticioso. Periodicidade diária \\
\hline 2 & Onze de junho & $1881-1889(11 \mathrm{sem})$ & Noticioso. Periodicidade diária \\
\hline 3 & A Discussão & $1881-1887$ (14 sem) & Comercial, noticioso. Periodicidade diária \\
\hline 4 & A Pátria 1887-1889 & $1887-1891$ (05 sem) & Comercial. Periodicidade diária \\
\hline 5 & Diario Popular & $1890-1900$ (13 sem) & $\begin{array}{l}\text { Órgão Republicano. Político comercial e } \\
\text { noticioso. Perio dicidade diária }\end{array}$ \\
\hline 6 & A Opinião Pública & $1896-1900$ (10 sem) & $\begin{array}{l}\text { Órgão dos interesses gerais - política } \\
\text { republicana. Periodicidade diária }\end{array}$ \\
\hline 7 & Folha da tarde & $1887-1888(04 \mathrm{sem})$ & Comercial. Periodicidade diária \\
\hline 8 & Diário de Pelotas & $1876-1889$ (27 sem) & $\begin{array}{l}\text { Noticioso, comercial. Em 1889, passa a ser } \\
\text { órgão do Partido Liberal do Sul da Província. } \\
\text { Periodicidade diária }\end{array}$ \\
\hline 9 & A Ventarola & $1875-1900$ (49 sem) & $\begin{array}{l}\text { Literário, ilustrado, humorístico, de interesse } \\
\text { geral da comunidade. A Ventarola acompanhará } \\
\text { o progresso do pensamento humano, sem, } \\
\text { entretanto, invadir "o sacro-santo lar da familia". } \\
\text { Periodicidade Semanal. }\end{array}$ \\
\hline
\end{tabular}




\begin{tabular}{|c|c|c|c|}
\hline № & Títulos & $\begin{array}{l}\text { Período (semestres } \\
\text { disponíveis } \\
\text { para pesquisa) }\end{array}$ & $\begin{array}{l}\text { Observações (Tipo de jornal, temas } \\
\text { privilegiados, periodicidade): }\end{array}$ \\
\hline 10 & Progresso Litterario & 1877-1888 (13 sem) & $\begin{array}{l}\text { Periódico de recreio e instrucção. } \\
\text { Periodicidade Semanal. }\end{array}$ \\
\hline 11 & Radical & 1890 (02 sem) & $\begin{array}{l}\text { Órgão Republicano, como folha essencialmente } \\
\text { política, o Radical defenderá sempre a causa da } \\
\text { Federação. Periodicidade Semanal. }\end{array}$ \\
\hline 12 & A Penna & 1884 (02 sem) & $\begin{array}{l}\text { Órgão do Clube Litterário Apollinário Porto } \\
\text { Alegre, tem por fim instruir seus consórcios nos } \\
\text { gêneros da litteratura comprehendida na sua } \\
\text { possibilidade. Não advoga princípios políticos, } \\
\text { podendo, porém, os colaboradores escrever } \\
\text { sobre o mesmo assunto. (06/7/1884). } \\
\text { Periodicidade Semanal. }\end{array}$ \\
\hline 13 & Tribuna Litteraria & 1882 (02 sem) & $\begin{array}{l}\text { Órgão das ideias novas. [busca] defender a } \\
\text { causa das letras e das sciencias [e] demonstrar } \\
\text { a necessidade das ações literárias e } \\
\text { scientíficas. Periodicidade Semanal. }\end{array}$ \\
\hline 14 & O Pervigil & 1882-1883 (04 sem) & $\begin{array}{l}\text { Tratando de todos os assumptos, de todas as } \\
\text { theses, sem entrar em profunda e detida } \\
\text { analyse, pois para tanto não tem forças, } \\
\text { O Pervigil será mais humorístico do que grave. } \\
\text { Periodicidade Semanal. }\end{array}$ \\
\hline 15 & Zé Povinho & 1882- (02 sem) & $\begin{array}{l}\text { Literário. "a encarnação do bello e do sublime, } \\
\text { o symbolo do trabalho e do progresso, } \\
\text { a irradiação das ideias úteis e generosas, } \\
\text { a bozina da sciencia através do espaço do porvir." } \\
\text { Periodicidade Semanal. }\end{array}$ \\
\hline 16 & Cabrion & 1880 (02 sem) & $\begin{array}{l}\text { Trata de assumptos politicos e sociaes. } \\
\text { Periodicidade Semanal. }\end{array}$ \\
\hline 17 & A Idea & 1878 (01 mês) & $\begin{array}{l}\text { Orgão do Club Litterário Democrata. } \\
\text { Periodicidade Semanal. }\end{array}$ \\
\hline 18 & Album Litterario & 1875 (02 sem) & $\begin{array}{l}\text { Periódico de recreio e instrucção. } \\
\text { Periodicidade Semanal }\end{array}$ \\
\hline 19 & Arauto das Letras & $1882-1883$ (03 sem) & $\begin{array}{l}\text { Literário. Circulava em Rio Grande e Pelotas. } \\
\text { Periodicidade Semanal }\end{array}$ \\
\hline
\end{tabular}

Fonte: Dados da pesquisa

As páginas dos jornais trazem discursos sobre a leitura, indicações, críticas a livros e escritores e possibilitam identificar alguns vestígios de apropriação feita pelos leitores. Muitos dos textos publicados nos jornais não apresentam autoria, sendo destinado o crédito ao jornal especificamente. Alguns jornais eram escritos por uma única pessoa, geralmente o proprietário, outros recebiam colaborações de vários escritores. Além dos jornais, também foram consultados atas e estatutos da Bibliotheca Pública Pelotense e das associações literárias. 
Para dar suporte à pesquisa, buscou-se abordar as noções e as metodologias utilizadas e difundidas por historiadores da leitura que trabalham sob a perspectiva da História Cultural, com ênfase em Roger Chartier, que apresenta como noções centrais a representação e a apropriação. A partir da análise dos jornais, foram identificados aspectos da produção e da circulação de materiais de leitura - livrarias, tipografias, autores e editores - em Pelotas, no século XIX. Optou-se por conservar a grafia original dos textos transcritos.

\section{O SURGIMENTO DAS BIBLIOTECAS PÚBLICAS NO FINAL DO SÉCULO XIX E A BIBLIOTECHA PÚBLICA PELOTENSE: APROXIMAÇÕES}

De acordo com Lajolo e Zilberman (2019, P.29):

Só por volta de 1840 o Brasil do Rio de Janeiro, sede da monarquia, passa a exibir alguns dos traços necessários para a formação e o fortalecimento de uma sociedade leitora: estavam presentes os mecanismos mínimos para a produção e circulação da literatura, como tipografias, livrarias e bibliotecas; a escolarização era precária, mas manifestava-se o movimento visando à melhoria do sistema.

Para Shapochnik (2005, p.230), ao longo do século XIX, houve a implementação de "novas bases institucionais da leitura de caráter público e privado, emblematizadas pelas bibliotecas e pelos gabinetes de leitura". Para o autor, esses locais de leitura "passaram a conviver simultaneamente com os antigos hábitos de narração de causos e da leitura oralizada no interior das moradas" (SHAPOCHNIK, 2005, p.230). Excluídas as bibliotecas eclesiásticas, as escolares, as de instituições de ensino superior e as corporativas, como as pertencentes à marinha, ao exército e aos museus, o pesquisador identificou 191 bibliotecas fundadas entre 1810 e 1900 em todo o território brasileiro.

Conforme Shapochnik (2005), após a instalação da Biblioteca Real (1810) no Rio de Janeiro e da Biblioteca Pública de Salvador (1811), o ritmo de implantação de instituições devotadas à leitura e ao empréstimo de livros era lento e atingiu somente quatro províncias até 1840. Contudo, foi identificado um crescimento que teve seu ápice nas décadas de 1860 e 1870. Com base nas informações pelo autor, elaborou-se a seguinte tabela: 
TABELA 1 - Bibliotecas públicas brasileiras fundadas no século XIX

\begin{tabular}{|c|c|c|c|c|c|}
\hline \multirow[t]{2}{*}{ Província } & \multicolumn{5}{|c|}{ Número de Bibliotecas } \\
\hline & Até 1840 & $1841-1860$ & $1861-1880$ & $1880-1900$ & Total até 1900 \\
\hline Bahia & 01 & 03 & 11 & 02 & 17 \\
\hline Rio Grande do Sul & 01 & 02 & 08 & 04 & 15 \\
\hline Pernambuco & 02 & 03 & 10 & 11 & 26 \\
\hline Rio de Janeiro & 04 & 04 & 19 & 04 & 31 \\
\hline Santa Catarina & - & 01 & 05 & - & 06 \\
\hline Sergipe & - & 01 & - & - & 01 \\
\hline Maranhão & - & 02 & 01 & - & 03 \\
\hline Minas Gerais & - & 04 & 05 & 07 & 16 \\
\hline Espírito Santo & - & - & 01 & - & 01 \\
\hline Goiás & - & - & 01 & - & 01 \\
\hline Mato Grosso & - & - & 01 & - & 01 \\
\hline Alagoas & - & - & 03 & 02 & 05 \\
\hline Ceará & - & - & 03 & 01 & 04 \\
\hline Rio Grande do Norte & - & - & 04 & - & 04 \\
\hline Pará & - & - & 08 & - & 08 \\
\hline Paraná & - & - & 13 & - & 13 \\
\hline São Paulo & - & - & 14 & 21 & 35 \\
\hline Amazonas & - & - & - & 02 & 02 \\
\hline Total & 08 & 20 & 108 & 55 & 191 \\
\hline
\end{tabular}

Fonte: Elaborada pela autora a partir de dados de Shapochnik (2005)

Nota-se que o período em que ocorreram mais implantações de bibliotecas no país foi entre 1860 e 1880, quando lideraram os estados do Rio de Janeiro e de São Paulo.

Dentro desse período, em 14 de novembro de 1875, foi fundada a Biblioteca Pública Pelotense, por iniciativa de um grupo de cidadãos liderados pelo redator do Correio Mercantil, Antônio Joaquim Dias. A biblioteca foi inaugurada com 960 volumes e funcionou, de início, num prédio oferecido por João Simões Lopes, o Visconde da Graça. (MAGALHAES, 1999, p.52). A Bibliotheca Pública Pelotense (BPP) representa um marco na história da leitura e da educação de Pelotas, pois se constitui numa representação da valorização da leitura no município de Pelotas no final do século XIX.

A criação da Bibliotheca Pública Pelotense, juntamente com a Biblioteca Real Nacional (1814), o Gabinete de Leitura do Rio de Janeiro (1837), a Biblioteca do Convento de São Bento, o Gabinete de leitura da cidade do Rio Grande (1846), o Gabinete de Leitura de Pernambuco (1871), a Biblioteca do Instituto Histórico e Geográfico Brasileiro (1847) e a Biblioteca Pública de Porto Alegre (1871), são destaques no livro "A formação da leitura no Brasil", de Lajolo e Zilberman (2019, p.244).

Para as autoras, o aumento do número de bibliotecas e gabinetes de leitura sugere "considerável encorpamento de malhas muito importantes no aparelho de leitura. 


\section{BITlOS E-ISSN 2236-7594}

Ainda insuficiente, porém, para construir um país [...]" (LAJOLO E ZILBERMAN, 2019, p.245). Essa observação vai ao encontro do que diz Schapochnik (2005, p.233), o qual afirma que "não se deve insistir no argumento denegador da existência de Bibliotecas e de clubes que favoreceram as práticas da leitura, pois os dados apresentados atestam a existência de uma rede de bibliotecas no território Brasileiro".

\subsection{A cidade de Pelotas e a criação da BPP no final do século XIX}

Para Becker (2007), no Rio Grande do Sul, com o crescimento urbano, formou-se um circuito cultural que vinculava cidades de dentro e de fora do RS, como, por exemplo, Rio de Janeiro, Porto Alegre e Pelotas, algumas das mais significativas concentrações urbanas da época.

De acordo com Magalhães, em Pelotas, no século XIX, existiu um movimento cultural que foi atribuído ao desenvolvimento, em seus arredores, da indústria do charque, no período compreendido entre 1779 até as primeiras décadas do século XX.

Essa maneira de ver a cidade de Pelotas, no século XIX, é reproduzida em inúmeros textos não só acadêmicos, como também jornalísticos e publicitários, até hoje. Termos como elite, aristocracia, riqueza, opulência sobressaem-se em trabalhos que fazem referência a Pelotas, no século XIX, e podem, por vezes, trazer uma imagem equivocada, levando a pensar em uma sociedade formada apenas por uma maioria de homens brancos, ricos e letrados. Sabe-se, no entanto, que Pelotas era formada por homens e mulheres provenientes de diferentes etnias, classes sociais e que exerciam diferenciadas práticas culturais.

O enriquecimento oriundo das charqueadas proporcionou o surgimento de práticas e valores socioculturais que exaltavam o gosto pelas artes, letras e ciências. Esse novo panorama possibilitou o crescimento da imprensa local. Assim, a atividade jornalística acompanhou esse processo. Houve o surgimento de jornais em profusão, em Pelotas, na segunda metade do século XIX, tanto aqueles com tendências políticas, como periódicos literários.

Em relação ao desenvolvimento literário na cidade de Pelotas, Magalhães afirma que o livro recebeu grande destaque no imaginário pelotense do século XIX. Segundo o autor, Pelotas enriqueceu a cultura rio-grandense de valores intelectuais e por isso recebeu o cognome de "Atenas do Rio Grande" (MAGALHÃES, 1993, p.25). 
Livrarias, teatros, jornais, bibliotecas, associações literárias e artísticas apareceram e foram se multiplicando na paisagem local, como confirmação do merecimento e da garantia de permanência do título orgulhosamente ostentado.

Durante o século XIX, a cidade de Pelotas conseguiu unir, ao mesmo tempo, boas condições econômico-urbanas e socioculturais. Essa convergência de fatores, em uma conjuntura histórica, foi capaz de configurar um verdadeiro apogeu. No entanto, não se pode esquecer, como afirma Peres, que:

Se por um lado Pelotas caracterizou-se por congregar uma elite que solidificou fortuna e fama para a cidade com a atividade saladeril, fazendo dela uma potência econômica e consequentemente política e cultural, por outro, tornou-se também um polo escravista (PERES, 1995, p.36).

\subsection{Por que criar uma biblioteca pública?}

Nos jornais pelotenses publicados durante todo o período estudado há referências à biblioteca, desde o movimento pela sua criação, passando pela fundação, criação de estatutos, relatórios mensais e anuais, comemorações de aniversários até crises enfrentadas para a sua manutenção.

Vale salientar que as publicações sobre a Bibliotheca, apesar de serem encontradas em todos os jornais, aparecem em maior frequência no jornal Correio Mercantil, o que se justifica pelo mesmo ter sido de propriedade de Antônio Joaquim Dias, um dos sócios fundadores da BPP e maior incentivador de sua criação.

Foram apresentadas várias justificativas para a criação da BPP, dentre elas, a que mais se destaca é a necessidade de instruir o povo. $O$ artigo publicado no jornal Correio Mercantil de 10 de novembro de 1875 mostra as primeiras manifestações sobre a criação da Bibliotheca. Esse artigo, além de apresentar uma paráfrase do texto publicado no Jornal do Comércio do dia anterior, transcreve o referido artigo, como uma forma de referendar a sugestão de criação de uma biblioteca pública.

Observa-se, nos dois artigos, uma comparação entre Pelotas e outras cidades, como Porto Alegre e Rio Grande, em virtude de já possuírem bibliotecas e gabinetes de leitura. Essa comparação pode ser observada nos excertos:

É tempo já de Pelotas imitar o exemplo de outras cidades, e nossa pujante mocidade dar cópia incontestesvel e patente de uma illustração e intelligencia (JORNAL DO COMMERCIO, 09 nov. 1875) 
Porto Alegre, Rio Grande e quase todas as localidades do interior do sul da provincia já de há muito possuem soberba bibliothecas e florecentes sociedades que offerecem uma instrução fácil e econômica a todos quantos cultivam o espírito e acompanham o progresso da civilisação.

Só Pelotas, a mais rica cidade da provincia, não possue nem uma bibliotheca, nem uma sociedade litteraria, nem um gabinete de leitura regularmente organisado.

Esta indiferença é prejudicial aos creditos e adiantamento da população.

(CORREIO MERCANTIL, 10 nov. 1875)

Os jornais mostravam a insatisfação com o fato de outras cidades já possuírem bibliotecas e Associações Literárias, enquanto, em Pelotas, nenhuma iniciativa parecia ter sido tomada. O apelo feito à comunidade pelotense era para que se tornasse possível a felicidade, através da instrução, do estudo e de conhecimentos sólidos. O apelo foi feito a pessoas de todos os níveis da sociedade, "sem distinção de classes".

A falta de uma biblioteca pública era considerada uma lacuna na vida intelectual da sociedade pelotense. Diante desse descontentamento, foi realizado um chamamento para que todos contribuíssem com a criação de uma biblioteca.

O Jornal Correio Mercantil, de 14 de novembro de 1875, apelava para que os leitores contribuíssem para a criação de uma biblioteca, justificando com o argumento de que todos que acompanhavam as evoluções do progresso e da atualidade e conheciam as vantagens que resultariam na criação de uma biblioteca pública deveriam contribuir.

Por conta dessa convocação à comunidade para auxílio na construção do prédio da BPP, encontraram-se dezenas de pedidos e de convites semelhantes aos seguintes:

Convite

Os obreiros do progresso público, que se interessam pela instrucção de todas as classes sociaes, são convidados para uma reunião que deve ter lugar no domingo próximo, 14 do corrente, às 11 horas do dia, nos salões da prestativa sociedade Terpsychore afim de tratar-se da fundação de uma bibliotheca pública nesta cidade. (CORREIO MERCANTIL, 12 nov. 1875)

Pedimos, pois, à generosa população de Pelotas, um obulo para o edifício da Bibliotheca Pública.

Ao pobre como ao rico, ao artista como ao comerciante, estendemos a mão e imploramos proteção para o espetáculo de hoje.

Não pedimos para nós, pedimos para o progresso e para a instrucção. (CORREIO MERCANTIL, 4 jan. 1879)

A mocidade de Pelotas precisa e deve entregar-se aos exercícios da intelligencia. Precisa e deve criar uma sociedade litteraria anexa a uma bibliotheca pública. (CORREIO MERCANTIL, 27 Jul. 1875) 


\subsection{Uma Biblioteca para o povo}

No período que SHAPOCHNIK (2005) identificou como o ápice da criação de Bibliothecas no país, em Pelotas, a criação da Bibliotheca era discutida diariamente, a instituição era considerada como o "templo dos livros" e ainda um remédio para os males. Mesmo após quase 20 anos de sua fundação, a biblioteca ainda era vista como "um edifício que guarda o livro - antídoto poderoso contra o estado funesto da ignorância, receptáculo de civilizadores" (CORREIO MERCANTIL, 08 maio 1894).

Schapochnik (2005) caracterizou as bibliotecas em três modalidades: bibliotecas públicas, bibliotecas associativas e bibliotecas populares. Segundo o autor, dois modelos biblioteconômicos definiam as bibliotecas públicas naquele momento criadas: o modelo anglo-saxônico, vinculado ao espírito associativo, favorecia uma rede de bibliotecas com objetivos determinados (religiosos, morais, filantrópicos); e o modelo francês, que caracterizava a biblioteca como um lugar aberto ao público de forma gratuita e com horário fixado. De acordo com o autor, tanto o horário quanto as instruções normativas desses espaços eram determinados de acordo com o público a eles destinados.

A primeira modalidade de biblioteca era de responsabilidade do estado, que atribuía a essas instituições "a função de conservação do acervo e a difusão do saber acumulado quase que exclusivamente a uma audiência constituída por eruditos e estudiosos locais" (SHAPOCHNIK, 2005, p.234).

A segunda modalidade era constituída pelos gabinetes de leitura ou bibliotecas associativas. Lugares de caráter privado e, em muitos casos, custeados por comunidades estrangeiras radicadas em terras brasileiras. Essas bibliotecas e gabinetes constituíam-se em espaços masculinos de sociabilidade. Todavia, o empréstimo de livros favorecia as práticas de leituras domésticas, as práticas de leituras femininas.

De acordo com o mesmo autor, uma terceira modalidade, implantada no Brasil a partir de 1870, foi chamada de biblioteca popular. Instituição pública, aberta a todo tipo de leitor. Entretanto, esse espaço legitimado de leitura era muitas vezes visto como moralizador e civilizador, uma vez que o acervo que o constituía estava vinculado à complementação da instrução elementar. A biblioteca popular acabava, nesse caso, reforçando "o papel delegado" à escola. Esse espaço de leitura era mantido por iniciativa de particulares (lojas maçônicas, letrados, negociantes, simpatizantes do abolicionismo, grupos políticos) com auxílios municipais e provinciais. 
Segundo a classificação exposta por SHAPOCHNIK (2005), pode-se dizer que a BPP teria as mesmas características das bibliotecas que compunham a terceira modalidade de bibliotecas implantadas no Brasil a partir de 1870 , denominadas de bibliotecas populares. A Bibliotheca não foi criada para ser um repositório, a exemplo de outras bibliotecas públicas que se formaram (ARAÚJO; OLIVEIRA, 2005), mas foi concebida para ser um "templo de luz" (PERES, 2002), com função similar ao que seria uma escola. Para os menos favorecidos, a necessidade de instrução poderia ser suprida com a criação de uma biblioteca que forneceria o "pão para o espírito" do artista e do “menino desvalido" (DIÁRIO DE PELOTAS, 04 dez. 1877).

É importante ressaltar que a criação e a construção da Bibliotheca partiram da iniciativa de membros da sociedade e não do governo, e que essa criação foi fruto de intensa campanha que era publicada nos jornais.

As sociedades em Pelotas

[...] Faltarão homens competentes para fundar e sustentar uma sociedade literária, uma bibliotheca pública?

O que falta é a iniciativa, a união da mocidade, o estímulo do estudo, a dedicação ao trabalho, o amor á ilustração. (CORREIO MERCANTIL, 27 Jul. 1875)

Além das manifestações na imprensa, foram realizadas quermesses a fim de angariar fundos para a construção do prédio, assim como livros eram doados pela comunidade para a formação do acervo.

Os bazares de prendas aconteciam frequentemente, e, por vezes, eram publicadas as listas de donativos com os nomes dos respectivos doadores. Para o bazar de prendas, eram doados utensílios como lenços, louças, arranjos de flores etc. (Correio Mercantil, 25 maio 1878; 02 jun.1878; 14 fev.1879; 13 maio 1882; 22 out.1885)

\begin{abstract}
Bazar de Prendas A'S FAMILIAS PELOTENSES

A comissão encarregada da construcção do edificio da Bibliotheca Publica Pelotense, necessitando de recursos para continuar aquella importante já bastante adiantada obra, confiada a generosidade das illustres familias pelotenses, recorre novamente á sua valliosa protecção para um bazar de prendas que se deve realisar no Domingo 2 de Março de 1879. (CORREIO MERCANTIL, 4 de Janeiro de 1879)
\end{abstract}

Havia doações de variadas formas, como, por exemplo, a do carpinteiro Manoel Gomes da Costa Parafita, que ofereceu seis dias de seu trabalho nas obras do edifício da Bibliotheca Pública Pelotense. O jornal Correio Mercantil afirmou que esse tipo de ação 
foi louvável, "muito mais quando ela parte de um artista" (CORREIO MERCANTIL, 15 set.1878).

A BPP passou a funcionar, em 1876, nos salões térreos de uma propriedade do Coronel João Simões Lopes, o Barão da Graça, posteriormente passou para o prédio que foi construído para abrigá-la definitivamente. Se compararmos a realidade de outras bibliotecas no país, a BPP não passou por tantas modificações de lugar, como generaliza Shapochnik (2005, p.243), quando afirma que houve uma existência errática, pois as bibliotecas foram submetidas a excessivos deslocamentos, "ocuparam as mais distintas instalações que incluíram desde as dependências de um hospital, quartos de hotéis até residências particulares, quando não compartilharam seu edifício e seus funcionários com outras instituições".

\subsection{As mulheres e a Bibliotheca Pública Pelotense}

$\mathrm{Na}$ ocasião de fundação da pedra fundamental para construção do prédio da BPP, Angélica Conceição Filha realizou um discurso caracterizado por uma leitura pública, que explicitou o significado que a criação de uma biblioteca trazia para a comunidade.

Em seu discurso, transcrito a seguir, observa-se a manifestação de um discurso positivista que atribui às bibliotecas e às escolas o poder de "exterminar" com atitudes e sentimento condenados, como, por exemplo, o despotismo, o crime e a intriga.

Nota-se, mais uma vez, a preocupação com o avanço intelectual dos pelotenses, reforçando a concepção de função principal da Bibliotheca, que seria de instruir a população.

Progresso, civilisação, luz e instrucção, eis o que symbolisa esse pedaço de granito collocado na terra de Pelotas para attestar perante a posteridade a dedicação de seus illustres habitantes pela nobilíssima causa do aperfeiçoamento da humanidade.

Grandioso exemplo de amor ao belo, ao útil e ao sublime!

Erguer monumentos ao trabalho e á instrucção, ensinar as classes desprotegidas da fortuna a pensar e sentir, a comprehender seus direitos e deveres, é de certo o que de mais nobre e generoso póde emprehender a iniciativa individual e o que de mais aprazível podem almejar as sociedades modernas.

A instrucção é o ideal dos espíritos avançados, a alavanca poderosa que ha de mover as aspirações dos séculos e converter em realidade as esperanças dos povos que se empenham pela liberdade de crenças e ideas perante a igualdade licita de regalias e obrigações.

Quando os altos potentados políticos e sociais comprehenderem esta verdade e se esforçarem no sentido de eleva-la á ordem das doutrinas 
e ciências positivas, cessarão para sempre as ambições exageradas, as lutas constantes entre a democracia e os fidalgos hereditarios, para predominar a garantia de interesse e o respeito ás posições justamente adquiridas.

Distribui em abundancia - instrucção e trabalho ao povo, que depende desses dois elementos de riqueza e felicidade - a firmeza de suas crenças, a consolidação de suas alegrias, o seu amor ás instituições, a homenagem mais sincera de apreço e admiração a tudo quanto se relacione com a virtude, a honra, o patriotismo e a moralidade.

No conchego intimo da família ou nas relações sociaes, a instrucção é tão necessaria ao espirito como o sol á vegetação e o ar á existencia.

Estudo e saber - eis os possantes motores da perfeição humana.

Estabeleçam-se bibliothecas e escolas por toda a parte; distribuíam-se livros e conhecimentos, que desapparecerão para sempre - o despotismo, o crime, a intriga, a inveja, o fanatismo, as paixões desordenadas e outros tantos sentimentos reprovaveis que se alimentam á sombra da ignorancia sustentada pela especulação dos mais atilados que fazem profissão do atrazo dos povos.

Rebrilhe a luz da instrucção como phanal da actualidade, que o futuro será um hymno de glorias ao progresso, ao bem e a sciencia.

Senhoras e senhores. - protegei a Bibliotheca Publica Pelotense - Rodeai-a de favores e benevolencias. - Concorrei para que sobre aquella pedra fundamental se erga pujante e beneficente, que tereis prestado o mais assignalado serviço de engrandecimento e aos creditos d'esta cidade.

$\mathrm{Da}$ instrucção e do trabalho, depende o progresso, a civilisação e a liberdade. (CORREIO MERCANTIL, 10 set. 1878)

O discurso da jovem inicia com as palavras progresso, civilização e instrução.

A autora sustenta a necessidade de os altos potentados aderirem à "ordem das doutrinas e ciências positivas", enfatizando que admira tudo que se relacione com a virtude, a honra, o patriotismo e a moralidade.

Recupera-se a ideia de biblioteca popular, que reforçaria a escola através do incentivo à instrução.

Outro discurso sobre a Bibliotheca foi proferido por Rita Lopes Lobato, em 1881, por ocasião da inauguração do novo prédio. Nesse discurso, a jovem repete a mesma representação de leitura e de biblioteca demonstrada na manifestação de Angélica, quatro anos antes, ou seja, as duas mulheres relacionam a criação da biblioteca à causa da instrução. A ideia de progresso oriunda da instrução para a coletividade.

Concerto vocal e instrumental da B.P.P.

Discurso da menina Rita Lobato Lopes

"Permiti que por ocasião de uma festa tão simpática, tão nobre e generosa ao mesmo tempo eu venha também expandir-me nesses votos que vejo e sinto aqui popular em meio de tão brilhantissimo concurso.

Diz-nos a experiência pela voz da história que um povo inculto jamais consegue levar-se, aparecer nos primeiros planos do vasto cenário da humanidade. 
E se não o que vem a ser um povo a revolver-se nas pesadas sombras da ignorância? Um quase que automato, uma aglomeração de indivíduos sem vontade própria, uma tumba que só sabe obedecer, porque ignora os seus direitos, uma população finalmente, falfa, do seu mais poderoso auxiliar para desenvolver-se em todos os ramos da atividade do mundo social.

Trabalhar pela causa da instrução é, senhores e senhoras, o maior serviço, a mais inestimável riqueza, o mais fecundo manancial que possamos franquear ao nosso semelhante. Aos benefícios bafejos da instrução tudo progride, tudo se retempera, no fervor dessas interminaveis lutas pela vida e bem estar.

[...]

Este belo edifício em cujo recinto achamo-nos agora em tão luzido concurso, ai está e ai ficará para atestar aos posteros que os pelotenses amam a instrução da mesma maneira porque se deve amar a liberdade.

Este monumento - esta Bibliotheca. conjuntamente com suas escolas, em breve, pela nunca desmentida generosidade deste povo, constituirá uma de suas maiores glórias.

Sim, a ideia desta instituição nasceu dele, por ele realizou-se e com ele se perpetuará na maemória dos tempos. [...]

Concorramos pois, sem distinções de sexos, nem preconceitos de posições sociais, para multiplicarr os meios da instrução popular consorciada com a ed. nacional, tem sido a base, a fonte das grandes civilizações no decorrer dos tempos.

[...] (CORREIO MERCANTIL, 23 abr. 1881)

No discurso proferido por Rita Lobato, fica mais evidente o caráter de popular dado (ou esperado) à Bibliotheca. Também ficam evidentes possíveis conflitos de gênero e de classe social presentes na sociedade pelotense quando a jovem solicita: "concorramos, pois, sem restrições de sexos, nem preconceitos de posições sociais".

A transcrição no jornal dos discursos realizados pelas mulheres demonstra a participação feminina e o reconhecimento da opinião das mulheres na esfera pública da cidade de Pelotas no final do século XIX. Esse fato merece atenção, pois, enquanto se discutia o que a mulher poderia ler, que ambientes poderia frequentar, algumas mulheres pelotenses tiveram espaço para defender a construção de um local para a promoção da leitura do povo.

Verifica-se o quanto a participação das mulheres na discussão sobre a criação de uma Bibliotheca é significativa, visto que alguns anos antes, 1875, era discutido se as mulheres, juntamente com as crianças, deveriam frequentar uma biblioteca específica para senhoras, como se observa no excerto:

Quero chegar à necessidade de uma biblioteca para senhoras, onde elas possam ler alguma coisa profícua, a sua felicidade doméstica, a sublime aspiração do sexo formoso; onde possam ler o Aimé Martin, o Paul-Jeannet, - Gasparin, ou Garret e tanta coisa que autores ilustres e mulheres instruídas tem escrito sobre a educação. (CORREIO MERCANTIL, 8 jan. 1875) 
Ao que tudo indica, no princípio, a Bibliotheca atendia apenas a homens e oferecia cursos noturnos para os trabalhadores da cidade. Peres (1995) apresenta detalhadamente isso na dissertação intitulada "Templo de luz: os cursos noturnos masculinos de instrução primária da Biblioteca Pública Pelotense: 1875-1915". Na dissertação, a pesquisadora descreve como se deu a criação da biblioteca com ênfase nos cursos noturnos oferecidos pela instituição.

\subsection{Relatos de uma fase de abandono}

Nas décadas de 1880 e 1890, verificam-se alguns indicadores de abandono pelo qual passava a biblioteca. Em relatório anual de 1885, publicado no Correio Mercantil de 11 de janeiro de 1886, pode-se visualizar que a frequência de visitantes havia sido reduzida em relação ao ano anterior, quando passou de 7.003 para 4.693 visitantes. Ao observar o relato sobre as obras consultadas, chama a atenção a descrição das obras:

Eis o numero de obras consultadas durante o anno:

Janeiro 139, fevereiro 121, março 115, abril 188, maio 113, junho 174 , julho 294, agosto 219, setembro 168, outubro 152, novembro 180 , dezembro 122.

Versaram essas obras sobre philosophia, linguistica, didactica, sciencias physicas e naturares, litteratura propriamente dita, novellas, romances, poesias, etc.

Lamento que não tenha sido maior o numero de obras consultadas, porquanto a nossa bibliotheca possue já avultadissimos thesouros onde a mocidade estudiosa póde adquirir grande cópia de conhecimentos, necessarios a quem se dedica á honrosa carreira das letras.

Havia aqui uma classificação das obras pelo assunto e pelo gênero, na qual se destaca a categoria "literatura propriamente dita" em comparação com novelas, romances e poesias.

Percebe-se um lamento em relação à baixa procura pela Bibliotheca e um incentivo à visita e à utilização daquele espaço, ou seja, de acordo com o relatório, o espaço previsto para a realização da leitura não estava sendo utilizado como se esperava.

Nota-se que havia picos em relação ao número de obras consultadas, sendo julho e agosto os meses em que se retiraram mais livros, meses de frio e de chuva, talvez próprios para se ficar em casa fazendo leituras.

Verifica-se que os meses de dezembro, janeiro, fevereiro, março e maio foram aqueles em que houve menos consultas. Considerando a possibilidade de os livros 
da biblioteca serem usados para leitura de lazer e também para estudos, pressupõe-se que o número de empréstimos tenha diminuído em virtude de que os estudantes estariam em férias, ou, ainda, nesses meses mais quentes, as pessoas poderiam procurar outros divertimentos ao ar livre, ao invés da leitura em casa ou na biblioteca.

\section{CONSIDERAÇÕES FINAIS}

Ao analisar os relatórios, notícias e comentários sobre a BPP nos jornais pelotenses, verifica-se que essa biblioteca foi e continua sendo uma das principais instituições culturais da cidade de Pelotas e do país, tanto pelo acervo que guarda quanto pela sua participação na história da leitura daquela sociedade.

Acompanhar a movimentação para a criação da Bibliotheca e para a sua manutenção possibilitou conhecer aspectos de uma comunidade que se preocupava com o livro e com o espaço destinado à leitura. Vê-se, na criação da Bibliotheca Pelotense, a materialização de uma cultura de valorização da leitura, dentro de uma sociedade que visava promover o seu desenvolvimento intelectual. Como afirma Peres (1995, p.89), a Bibliotheca Pública Pelotense "também teve um caráter de associação literária lá aconteciam conferências públicas, defesas de "teses" sobre os mais variados temas, funcionavam clubes e sociedades literárias - de escolas -, além dos cursos noturnos". Assim, com características de uma biblioteca popular, a criação e manutenção desse espaço evidenciado pelos jornais pelotenses no último quartel do século XIX dá indícios de uma sociedade complexa, que tinha a leitura como objeto de debate sobre diferentes representações e como prática social já estabelecida.

\section{REFERÊNCIAS}

ABREU, Márcia. Prefácio. In: MELO, Orlinda C. A invenção da cidade: leitura e leitores. Goiânia: Editora UFG, 2007.

ARAÚJO, Eliany Alvarenga; OLIVEIRA, Marlene. A produção de conhecimentos e a origem das bibliotecas. In: OLIVEIRA, Marlene de (Coord.). Ciência da informação e biblioteconomia: novos conteúdos e espaços de atuação. Belo Horizonte: Ed. da UFMG, 2005.

BASTOS, Maria Helena Câmara. Leitura das famílias brasileiras no século XIX: o jornal das famílias (1863-1878). Revista Portuguesa de Educação, Braga (Portugal), v.15, n.2, p.169-214. 2002.

BECKER, Gisele. A construção da imagem da prostituição e da moralidade em Porto Alegre pelo jornal Gazetinha : uma análise dos códigos sociais segundo a Hipótese de Agendamento (1895-1897). 2007. Tese (Doutorado em Comunicação) Pontifícia Universidade Católica do Rio Grande do Sul. Porto Alegre, 2007. 
CHARTIER, Roger. À beira da falésia: a história entre certezas e inquietude. Porto Alegre: Editora da UFRGS, 2002a.

CHARTIER, Roger. A aventura do livro do leitor ao navegador. São Paulo: Editora da UNESP, 1999.

CHARTIER, Roger. A história ou a leitura do tempo. Belo Horizonte: Autêntica, 2009.

CHARTIER, Roger. A ordem dos livros: leitores, autores e bibliotecas na Europa entre os séculos XIV e XVIII. Tradução de Mary Del Priore. Brasília: Editora da UnB, 1994.

CHARTIER, Roger. Do livro à leitura. In: CHARTIER, Roger (Org). Práticas da leitura. 2. ed. São Paulo: Estação Liberdade, 2001.

CHARTIER, Roger. Os desafios da escrita. São Paulo: Editora da UNESP, 2002b.

CUNHA, Jaqueline Rosa da. Arauto das Letras (1882-1883): uma amostra da expressão literária da região sul rio-grandense. 2004. Dissertação (Mestrado em Letras) Departamento de Letras e Artes, Universidade Federal do Rio Grande, Rio Grande, 2004.

GONÇALVES, Renata Braz. Livros e leitura na cidade de Pelotas-RS no final do século XIX: um estudo através dos jornais pelotenses (1875-1900). 2010. 237f. Tese (Pós-Graduação em Educação), Universidade Federal de Pelotas. Disponível em:

http://guaiaca.ufpel.edu.br:8080/handle/123456789/1616. Acesso em: 15 set. 2020.

LAJOLO, Marisa; ZILBERMAN, Regina. A formação da leitura no Brasil. São Paulo:

Ed. Unesp, 2019.

MAGALHÃES, Mario Osório. História e Tradições da Cidade de Pelotas. 3.ed. Pelotas: Armazém Literário, 1999.

MAGALHÃES, Mario Osório. Opulência e cultura na província de São Pedro do Rio Grande do Sul: um estudo sobre a história de Pelotas (1860-1890). Pelotas: Editora UFPel, Livraria Mundial, 1993.

PERES, Eliane. Templo de luz: os cursos noturnos masculinos de instrução primária da Biblioteca Pública Pelotense: 1875-1915. 1995. Dissertação (Mestrado em Educação). Faculdade de Educação, Universidade Federal do Rio Grande do Sul. Porto Alegre: 1995.

Templo de Luz: os cursos noturnos masculinos de Instrução primária da Biblioteca Pública Pelotense (1875-1925). Pelotas: Seiva Publicações, 2002.

PESAVENTO, Sandra Jatahy. Cidades visíveis, cidades sensíveis, cidades imaginárias.

Rev. Bras. Hist., São Paulo, v. 27, n. 53, Jun. 2007. Disponível em:

$<$ http://www.scielo.br/scielo.php?script=sci_arttext\&pid=S0102-

01882007000100002\&Ing=en\&nrm=iso >. Acesso em: 04 jun. 2020. doi:10.1590/S010201882007000100002.

ROCHE, Daniel. As práticas de escrita nas cidades francesas do século XVIII. In: CHARTIER, Roger (Org). Práticas da leitura. 2. ed. São Paulo: Estação Liberdade, 2001.

SCHAPOCHNIK, Nelson. A leitura no espaço e o espaço na leitura. In: ABREU, Márcia \& SCHAPOCHNIK, Nelson (orgs.). Cultura letrada no Brasil: objetos e práticas. Campinas, SP: Mercado das Letras, Associação de Leitura do Brasil (ALB); São Paulo, SP: Fapesp, 2005.

VILAR, Socorro de Fátima Pacífico. Modos de ler e de escrever nos jornais e periódicos brasileiros da primeira metade do dezenove. Sociopoética. v.1. n.1. Disponível em:

<http://www.uepb.edu.br/eduep/sociopoetica/publicacoes/v1n1pdf/15\%20Socorro\%20de\%20F+\% EDtima\%20Pac+\%A1fico\%20Vilar\%20.pdf>. Acesso em: 15 abr. 2020.

ZILBERMAN, Regina. A leitura no Brasil: sua história e suas instituições. [201?]. Disponível em: http://www.unicamp.br/iel/memoria/projetos/ensaios/ensaio32.html. Acesso em: 21 fev. 2020. 